\title{
Editorial
}

\section{Two announcements, an apology and some food for thought - Not totally unconnected}

The first and most prodigious announcement has to do with the future of Henry Stewart Publications and its stable of journals. The latter — or, at least, those in business and related fields - have been acquired by Palgrave Macmillan, the academic and professional publishing division of Macmillan Publishers Ltd.

This represents a considerable synergy and can only prove positive for all concerned: for the journals — which will now benefit from exposure to a much wider community of potential readers and subscribers; for those of us who edit the journals - as we will have greater resources to draw upon; and, ultimately, for you, the reader, as it is to be expected that the additional cross-fertilisation between journals will increase their reach and mean the inclusion of contributions from a much wider range of authors and experts.

So far, so good.

The second announcement is rather less exciting and has to do with a shift in emphasis for the journal. Nothing quite as dramatic, but important nonetheless for those who rely on the journal as a source of informed experience in the areas of database marketing and customer strategy.

That is, we have been planning, for some while, a shift towards practice and experience. We have no intention of abandoning our academic roots entirely, for, at the end of the day, it is our strong links with the academic community that guarantee the journal remains factual and grounded in reality. Some publications rely largely on the interesting and highly erudite input of consultants. Certainly, they have the ability to be more flexible, much more 'of the moment'.

What may be perceived as strengths in some quarters, however, is not really the stuff from which lasting business improvement is gained because publications that lack a research base or independent review to pour cold water on some of the more far-fetched theories will be fickle creatures, subject to the latest fads and fancies in the area - and as likely to mirror poor practice as counsel against it.

So we are looking to build up the proportion of case studies and 'best practice papers' in the journal. We will most definitely be seeking input from those 'at the sharp end': individual managers, directors and consultants who have put into practice some aspect of customer relationship management (CRM) and who are able to talk knowledgeably about the obstacles surmounted as well as the benefits realised. At the same time, we are going to continue to subject such papers to the rigours of independent review, and we will continue to publish material that has behind it a respectable academic pedigree and which expands the breadth of knowledge in this area. 
This shift is prompted, in part, by a second realisation: our remit is global; yet - and this is as much my responsibility as anyone else's - we do have a tendency towards anglo-centrism. The UK, the USA and the rest of the English-speaking world provide a major part of our input.

Whilst that may be acceptable for some matters (in theory, best practice in systems implementation is best practice no matter where in the world you are), there are many areas where this is not the case. Legal considerations, for instance. Far too much of our debate on data protection focuses on the UK, with some regard given to the USA and, occasionally, Europe, but the state of play in, say, China or Japan must remain a mystery to our readers.

Work we have published in the past demonstrates the importance of cultural differences when it comes to topics as diverse as branding and direct marketing. Research shows that attitudes, practice and effectiveness of a range of techniques vary across the world. This we have not always captured as fully as we should or could.

Part of the turn towards practice papers, therefore, is an effort on our part to tackle many different perspectives on different issues. In future - and I hope that you, the reader, will hold me to this - if we publish a paper on practice in North America, we should be seeking to compare and contrast this with similar practice in India or Australia.

All of which brings me to the apology. We had hoped to make this, the start of a new volume, the first issue to take this approach. Our aim was to put together a special issue on the topic of market resource management (MRM or, in some quarters, MOM).

We had hoped - indeed, we have been highly successful in commissioning writers to set down their experiences in this area and we have a range of interlinked best practice papers ready to roll - almost!

Two disasters struck. The first, which perhaps we ought to have foreseen, was the summer holidays. In horror movie terms, there is little that can compare to the hair-tearing screaming nightmare of a deadline to hit - and a long list of authors who have all, simultaneously, decided to disappear for two weeks in the sun. Memo to self: never, ever again attempt to commission a complex edition over the summer holidays.

So far, so predictable. What was much less predictable was the long delay introduced by the press offices of one or two of the organisations involved. It is a tendency I have noticed over the years: whenever the press office or PR agency get involved, one is up for a fight.

Because, whilst their job is to show their organisation in the best possible light, admitting to no difficulties and giving away as little as possible, the meat and drink of this journal is the journey, the implementation, the obstacles overcome, the learnings along the way. We are not here to provide excellent PR for organisations. Indeed, the ideal practice paper is one that begins with an issue a failure, even - and demonstrates robustly how this was tackled. Also, whilst I recognise the need for confidentiality, I think that at times organisations protest too much.

When, some years ago, I worked in the insurance industry, my employer - a major direct insurer - had in place a massive programme of 'mystery shopping'. That is, it paid various research agencies to phone its main competitors on a monthly basis and extract large numbers of quotes from each. These quotes were then pulled together by our statisticians and fed into a model that aimed to demonstrate where we were competitive and where not. 
This project required us to obtain around 1,200 quotes per month. Our main competitors were doing the same. So, quite apart from the expense of doing the research, we were all using up significant amounts of each others' call centre resources to obtain quotes that would never go anywhere.

The solution? Eventually, we decided this was a waste of time and resources. About a dozen of the country's largest direct insurers got together and appointed an independent research agency. We charged them with obtaining data from each of us and then pooling that data in order that we could obtain the same picture as we had previously obtained from our mystery shopping at far less cost and involving far less hassle than before.

Co-operation, in even the most competitive of areas, made perfect business sense.

So, too, with best practice. It is very easy to read about it: very easy to understand the principles of it, and - if someone reads a paper in this journal and wishes to put its principles into practice - I wish them the best of luck. It is rarely very easy to do: first, because lessons learnt in one organisation will never transfer perfectly to another and secondly because, always, the devil is in the implementation.

Most organisations know what they ought to be doing. The big issue lies not in finding out what they should be doing, but in doing it.

So, welcome to Volume 13 of the Journal of Database Marketing and Customer Management Strategy. Under new management, starting out on a new direction, and bringing to you a mix of practice and academic papers.

One area where we have taken a fresh look is that of data protection, with separate contributions from Bryan Foss and Alison Bond, and Jennifer Kirkby.

A major contribution in this issue comes from Ralph van Bentum and Merlin Stone, who take a look at customer relationship management and the impact of corporate culture across Europe. Andy Wood takes a practitioner's view of what database analysis can tell you, whilst Jim Laiderman provides a structured approach to $\mathrm{B} 2 \mathrm{~B}$ segmentation.

Further material comes from Tyrone Jackson, looking at the progression of CRM from art to science. Finally, our legal focus this issue is on the patenting of databases.

JOHN OZIMEK Managing Editor 